\title{
La deuda inglesa de México en el siglo XIX ${ }^{1}$
}

\section{Silvestre \\ Villegas Revueltas \\ IIH-UNAM}

Los procesos de emancipación de la América Hispana, desde sus inicios entre 1808 y 1810 hasta los triunfos irreversibles a lo largo de los años veinte, tuvieron importantes connotaciones internacionales. La Revolución Francesa y la era napoleónica acabaron con el decadente Imperio Español. Inglaterra, por su lado, triunfante de las guerras europeas, era además la potencia industrial del momento. Su objetivo era buscar territorios y abrir espacios para vender sus productos británicos y con ello ejercer paulatinamente una influencia determinante en el mundo. El continente americano, representaba una inmensa área geográfica 1lena de posibilidades mercantiles.

\section{Las bases}

Una vez concluido en 1821 el movimiento militar que tenía por objetivo lograr la consumación de la independencia de México, resultaba indispensable que el nuevo estado tuviera la fortaleza y soberanía suficiente para ejercer diversas acciones de gobierno. México fracasó con el experimento imperial de Agustín de Iturbide porque no contaba con la fuerza necesaria para sobreponerse a los generales que lo habían secundado desde el Plan de Iguala, no controlaba el accionar de las provincias que conformaban el imperio y sobre todo no tenía legitimidad, pues su gobierno había sido el resultado de un alzamiento militar. La Constitución de 1824 y el primer gobierno republicano encabezado por Guadalupe Victoria consolidaron la independencia política.

En lo tocante al ámbito financiero, el país se independizó reconociendo - de hecho- la deuda colonial que sumaba varios millones de pesos, sin embargo, el problema era lo raquítico de los ingresos con los cuales debían
Las presentes reflexiones son el resultado de una investigación de largo plazo la cual se ha materializado en varios artículos, conferencias y en el libro Deuda ydiplomacia. La relación México-Gran Bretaña, 1824-1884. México, IIH-UNAM, 2005. En donde el lector podrá encontrar la bibliografía que sustenta lo que se suscribe en las siguientes páginas. 
solventarse los gastos diarios de la administración. En 1823 el Congreso autorizó contratar en Londres un préstamo por ocho millones de pesos.

Después de un año de negociaciones, el agente mexicano Francisco Borja Migoni llegó a un acuerdo con la casa Goldschmidt, quien prestaría en un lapso de 15 meses dicha cantidad en efectivo, pero México se haría acreedor a una deuda cercana a los quince millones de pesos, la cual fue resultado de la emisión de bonos y el bajo precio que los mismos tuvieron en el mercado de valores inglés.

En enero de 1825, en la ciudad de México, el gobierno y los representantes del banco Barclays Richarson \& Co., negociaron otro préstamo. Por esta operación el país recibió en efectivo cerca de doce millones de pesos a cambio de una cantidad en bonos de alrededor de quince millones de pesos. Lo anterior quiere decir que para febrero de 1825 México había contratado dos créditos, reconociendo una deuda en bonos al portador por un poco más de treinta y dos millones de pesos, cuando el Congreso solamente había aprobado solicitar un crédito por ocho millones.

Si bien los anteriores comentarios hacen patente las condiciones usurarias en que fueron contratados tales préstamos, resulta esencial exponer en qué se gastaron y para qué sirvieron dichos créditos.

México contrató préstamos a 30 años para enfrentar urgencias del momento. El dinero sirvió para pagar al ejército y a sus comandantes, para comprar armas, barcos y municiones. Sin embargo, hay que reconocer que estas últimas adquisiciones eran el resultado de una posible y temida reconquista por parte de España que se haría patente en la llamada invasión de Isidro Barradas, aventura cuya derrota final se debió a la acción conjunta de los generales Antonio López de Santa Anna y Manuel Mier y Terán en 1829.

El pago efectivo de la deuda era difícil, pues el país no contaba con un sistema moderno de recaudación de impuestos y no producía lo suficiente para generar ingresos importantes, como es el caso de los gravámenes por concepto de exportación e importación. A lo largo de 50 años el país no tuvo los recursos necesarios para pagar puntualmente el capital y los intereses que generaban los créditos Goldschmidt y Barclay. 
Los préstamos ingleses tuvieron una finalidad de carácter internacional. El gobierno británico y su ministro de asuntos exteriores, George Canning, consideraron que una entidad política, sujeta a crédito en grandes cantidades (préstamos mayores que los otorgados a Austria, Dinamarca y Portugal), debía de reconocérsele su independencia dentro del concierto de las naciones. Ello quiere decir que los dos préstamos aceleraron el hecho de que México fuera considerado como un cuerpo distinto y aparte de España.

E1 reconocimiento británico a las recientes repúblicas hispanoamericanas, el 31 de diciembre de 1824, hizo más difícil, aunque no imposible, que España o Francia intentaran recuperar las antiguas colonias españolas. Los dos países no podían enfrentarse a Inglaterra pues controlaba los mares especialmente del Atlántico. El sentido de la declaración Canning hizo que el crédito de México, Colombia, Argentina, Perú y Centroamérica aumentara en la Bolsa de Londres, que los bonos subieran de precio y que al mismo tiempo dichos estados nacieran endeudados. Más aún, el gobierno inglés vio en tales contratos y en el reconocimiento de la independencia de los países hispanoamericanos, la oportunidad para penetrar comercialmente en esta cerrada zona.

México firmó en 1826 el Tratado de Amistad Comercio y Navegación que reguló las relaciones comerciales entre ambas naciones hasta el año de 1867. Con tal acuerdo, mineros ingleses en búsqueda de plata, mercaderes de telas, comerciantes de productos manufacturados y de artículos industriales comenzaron a llegar a la República.

De esta manera, entre 1824 y 1826 México se ligaba a la comunidad internacional de naciones como un estado soberano e independiente, con capacidades para contratar préstamos a largo plazo y como un lugar con grandes expectativas para el comercio y la inversión. En este sentido se completaba la independencia que había iniciado Miguel Hidalgo y que Agustín de Iturbide y Vicente Guerrero habían concluido. Sin embargo, la Independencia formal y el reconocimiento internacional eran un asunto insuficiente, pues faltaba una reforma dentro del país que modificara, tanto las relaciones sociales desde el ámbito familiar y en el trabajo, como la supresión de una 
sociedad eminentemente clasista, corporativa y racista; aunado todo ello a un ejercicio efectivo de los derechos políticos y al afianzamiento de la democracia.

\section{Las dificultades}

Los golpes de estado, los alzamientos militares y la rivalidad entre gobernadores-caciques y comandantes militares, aunado a la guerra con Texas y posteriormente con Estados Unidos, provocaron que los gobiernos mexicanos consumieran buena parte de sus recursos financieros en el mantenimiento de un ejército que propiciaba un clima de inestabilidad política. A esto último se agregó el enfrentamiento entre los gobiernos ubicados en la capital de la República y los poderosos intereses regionales y locales que muchas veces estuvieron en abierta oposición y propiciaron que quedaran sin efecto aquellas medidas que el centro dictaba. Tal oposición, entre otras cosas, afectó el pago puntual a sus préstamos internacionales.

En 1828 México no pudo pagar el servicio de la deuda (los intereses) por lo que anuncia la primera suspensión de pagos y en consecuencia la primera moratoria. Con ello el país perdió su crédito con Gran Bretaña, se cerraron las puertas del financiamiento externo y sólo dos años más tarde el gobierno mexicano - por medio del banquero Alexander Baring-, 1legó a una renegociación con los tenedores de bonos mexicanos contratados en un inicio con la casa Goldschmidt y el banco Barclay; este último estaba quebrado, con ello desapareció el fondo de amortización mexicano que sumaba miles de libras esterlinas.

El acuerdo de 1830 unificó la deuda en un fondo común que ha sido conocido y etiquetado como La Deuda de Londres y a los acreedores británicos se les conoció como los London Bondholders.

Entre 1830 y 1850 el gobierno mexicano pagó capital e intereses, sin embargo, las suspensiones en 1837, 1839-1840 y de 1845 hasta 1850 modificaron radicalmente la relación: entre las autoridades del país, los London Bondholders y el gobierno británico. La correlación de estas tres partes debe ser explicada, pues condicionó las relaciones financieras y diplomáticas entre ambos países hasta la década de los ochenta, ya en pleno porfiriato. 
Desde los préstamos de 1824-1825, el acuerdo con Baring en 1830, así como las sucesivas renegociaciones de la deuda en los años treinta y cuarenta, cada uno de los acuerdos hipotecó, para el servicio de la deuda, porcentajes específicos de los ingresos recaudados en las aduanas fronterizas y marítimas por concepto de impuestos a la importación de productos provenientes, fundamentalmente de Europa, 1o mismo que a los de exportación focalizada en barras y monedas de plata, en menor medida aplicadas a las maderas preciosas, grana y otros productos naturales. Muchas veces y a lo largo de estos años los principales puertos del país: Matamoros, Mazatlán, Veracruz, Tampico, San Blas y Acapulco además de pueblos fronterizos como Piedras Negras, estuvieron, fuera del control del gobierno de la ciudad de México. Esta situación provocaba que los "revolucionarios" se apropiaran del dinero recaudado en las aduanas, incluyendo los fondos para ser remitidos a Londres. Lo cual propició que el incumplimiento de los pagos fuera una realidad, no por culpa del gobierno central, sino como resultado de la autonomía con que se manejaban los intereses regionales. Éstos a su vez argumentaban que las apropiaciones eran el resultado del abandono en que los dejaba el gobierno mexicano. Vid. La guerra contra "el indio bárbaro".

La inestabilidad que México vivía, tuvo repercusiones financieras que dieron como resultado dos sucesos importantes.

En el primero, el gobierno inglés, por medio de los ministros plenipotenciarios, cónsules y vicecónsules apostados a lo largo de la República Mexicana, decidió oficialmente apoyar a los London Bondholders, este apoyo consistió en que la deuda contratada en Londres, pasara de ser un contrato privado a un tema de convenciones diplomáticas entre dos países soberanos, en desigualdad de circunstancias. Gran Bretaña era la potencia del siglo xix y México era una nación joven con eminentes problemas sociales.

En el segundo, la inestabilidad política, originó un importante número de atentados contra la vida y la propiedad de súbditos británicos radicados en el país, provocando que los daños y perjuicios en contra de ingleses se convirtieran en una cuestión respaldada por el gobierno británico; con dimensiones importantes, dado que el 
monto generado por los daños, se convirtió en la segunda deuda de México con Inglaterra. Conocida a partir de 1842, como las Reclamaciones Británicas o English Convention Debt, cuando el ministro Packenham obligó al gobierno mexicano a comprometerse a pagar un monto cercano a los cinco millones pesos, como compensación a los daños.

Durante la guerra con Estados Unidos, -en 1847-, el embajador mexicano en Londres, José María Luis Mora y el inversionista mexicano de origen inglés Tomás Murphy, 1legaron a un acuerdo con los acreedores estableciendo la London Debt en poco más de diez millones de libras o cincuenta millones de pesos, convirtiéndose ésta suma en la única reconocida por todas las partes, inclusive, en las renegociaciones de 1886. Pero no fue sino hasta 1850 cuando el gobierno del presidente José Joaquín de Herrera sufraga aproximadamente tres millones de pesos (cantidad que comprendían el pago de todos los intereses atrasados hasta la fecha) con el dinero que Estados Unidos dió al gobierno mexicano como parte de la indemnización por los territorios perdidos de California, Sonora y Nuevo México. Un año después el gobierno del presidente Mariano Arista renegoció con el embajador británico el monto de las reclamaciones británicas originalmente establecidas en 1842; tal acuerdo se conoce como la Doyle Convention. Lo anterior quiere decir que en el lapso de 1850-1851, La Deuda de Londres, aunque vigilada por Gran Bretaña continuaba siendo un acuerdo privado entre México y el Committee of Spanish American Bondholders. En cambio la convención Doyle o English Convention Debt era desde tiempos de Packenham una deuda protegida por el gobierno de su majestad británica. Dicha modificación había comenzado bajo el gobierno de Lord Aberdeen y posteriormente bajo el del Lord Palmerston quien en 1848 había declarado que si bien era costumbre del gobierno británico no entrometerse en asuntos financieros y comerciales desarrollados por súbditos ingleses, ésta política tenía lugar a modificación cuando los gobiernos extranjeros eran incapaces de cumplir con sus obligaciones internacionales, o bien existía una discriminación en los aparatos de administración de justicia, entre los locales y los súbditos británicos. 
La declaración del premier Palmerston en lo concerniente a México tiene dos lecturas. Desde el primer incumplimiento en 1828 hasta fines de los años cuarenta, la República fue incapaz de observar plenamente los términos estipulados con los acreedores. La discriminación aludida entre locales y extranjeros fue sin duda alguna una consecuencia de 1o anterior. Cuando el gobierno mexicano en 1830 perdió su crédito en Londres, las administraciones buscaron vías para poder hacerse de dinero entre los acaudalados mexicanos y los comerciantes extranjeros domiciliados en la República.

Es un hecho que las administraciones públicas mexicanas pagaban prontamente los préstamos domésticos y ello se debía a dos razones. Primero y más importante, si no liquidaban dichos adeudos no podrían en el futuro negociar otros empréstitos y el gobierno se vería en una disyuntiva: o dejar de cumplir con sus obligaciones administrativas o ejecutar préstamos forzados. Segundo, el poder de presión desarrollado por los acreedores domésticos 1lamados despectivamente "agiotistas", era mucho mayor que el ejercido tanto por los London Bondholders como por los diplomáticos británicos hasta el inicio de los años cincuenta. En otro sentido era evidente que aunque México liquidaba muchos empréstitos, la bancarrota del gobierno mexicano era una cuestión de tiempo, debido a los conflictos políticos, a la poca producción, al escaso consumo de la población mexicana, a la reducida base tributaria y al corrupto e ineficiente sistema fiscal.

\section{La ruptura}

La Guerra de Reforma, la Intervención Francesa y e1 Imperio de Maximiliano abarcan el periodo 1858-1867, cambiaron de raíz tanto las relaciones diplomáticas entre México y Gran Bretaña como el carácter de La Deuda de Londres, La Convención Inglesa y las Reclamaciones Británicas no reconocidas por los gobiernos mexicanos después de 1852 .

Los gobiernos de Félix Zuloaga y Miguel Miramón se establecieron en la ciudad de México y fueron sucesiva 
mente reconocidos diplomáticamente por Francia, España e Inglaterra. El de Benito Juárez se posesionó del Puerto de Veracruz y fue reconocido por Estados Unidos. Nunca antes dos regímenes se habían ostentado simultáneamente como las verdaderas autoridades de la República. Es evidente que la Guerra de Reforma involucró a distintas potencias que tenían intereses contrapuestos respecto a México y que también estaban enfrentadas, considerando la relación de fuerzas en el ámbito internacional.

Antes de que tomara forma la intervención de Francia, Charles Otway, ministro inglés, desarrolló entre los conservadores la idea de promover una expedición británica para derrotar a los liberales y buscar un nuevo sistema de gobierno, -entiéndase una monarquía constitucional. Este gobierno debería reorganizar al país para que México volviera a ser no solamente un país respetado, sino apto para las inversiones de un nuevo orden industrializado, y ser puntual en los pagos con sus diversos acreedores. Sin embargo, al mismo tiempo y en contraposición al proyecto de Otway, el gobierno británico decidió entrar en pláticas con el régimen de Juárez.

El objetivo era que México comenzara a pagar de nueva cuenta las dos deudas inglesas, pago que se había suspendido desde 1854, etapa que coincide con los gastos provocados por la Revolución de Ayutla. El proceder del gobierno de su majestad planteaba un problema jurídico, pues Gran Bretaña había reconocido como gobierno de jure a los conservadores y al mismo tiempo negociaba el pago de la deuda - el tema bilateral- con unas autoridades en el puerto de Veracruz, que de acuerdo al derecho internacional, a lo sumo podrían considerarse como una autoridad de facto o simplemente en condición de beligerante. Se agregaba el elemento de que los liberales estaban en posesión de la plaza que más ingresos producía; ello en el entendido de aquellos recursos previamente hipotecados para el servicio de las diversas deudas.

En 1859 fue firmada la Convención Dunlop y un año después la Convención Aldham. Para Londres, lo importante de ambos tratados fue que consiguieron ocupar en un mayor porcentaje los fondos de las aduanas destinados al pago de los adeudos ingleses. Por otro lado y con la 
presente negociación, el gobierno de Whitehall se convertía en garante no sólo de la English Convention Debt sino también de la London Debt. Asimismo y de acuerdo al departamento jurídico del Foreign Office en Londres, el pago puntual se consideró como la base jurídica para reconocer al gobierno de Benito Juárez como la legítima autoridad del país. En cambio, de acuerdo a la lectura del Ministerio de Relaciones Exteriores, al instalarse en la ciudad de México el gobierno liberal, ambas partes se dedicarían a negociar una verdadera convención, misma que no estuviese marcada por la presencia disuasiva de la marina británica en playas veracruzanas. Sin duda ambas interpretaciones presagiaban un conflicto de intereses.

Juárez ocupó la capital del país en enero de 1861, en julio su gobierno declaró la suspensión de pagos y una moratoria por dos años respecto a los acreedores nacionales y extranjeros; días después los ministros plenipotenciarios de Francia e Inglaterra rompieron relaciones con México. En octubre se firmó la Convención de Londres donde Inglaterra, Francia y España decidían intervenir militarmente la República para hacerse pagar deudas no cubiertas. En diciembre tropas españolas ocupaban Veracruz y para marzo de 1862 Manuel Doblado, ministro del exterior del gobierno juarista, reconocía todos los reclamos ingleses, autorizaba el manejo de las aduanas por parte de agentes británicos y prometía recibir fondos provenientes de Estados Unidos para cubrir los adeudos de la Deuda de Londres y de la Convención Inglesa.

El gobierno de Lord Palmerston rechazó esta última oferta, pues involucraba a un tercer país, Estados Unidos, envuelto para entonces en una guerra civil -confederados y unionistas - y porque además temía que México, al no poder solventar el pago fuera absorbido por Estados Unidos.

Las negociaciones diplomáticas se cerraron, se ganó la batalla del 5 de mayo en 1862, un año después, la ciudad de México era ocupada por tropas francesas y el gobierno de Juárez iniciaba su peregrinaje por varias ciudades del país.

En apariencia y de acuerdo a lo que afirman muchos historiadores, la falta de pagos a los acreedores ingleses produjo la intervención europea en México. Sin embargo, 
un detallado análisis de los sucesos acontecidos entre 1860 y 1862 muestra que el objetivo real de las potencias era la instalación de una monarquía, puesto que para los países europeos, los gobiernos republicanos, ya hubiesen sido administraciones federales o centralistas, conservadoras o liberales, habían demostrado su ineficacia para desarrollar un país.

La industrialización de la segunda mitad del siglo XIX; el inicio de la guerra civil americana; el proyecto napoleónico de establecer una nación latina fuerte que contrapesara el avance anglo-sajón; los proyectos francés e inglés por establecer en México una banca nacional; aunado al pretexto de la deuda mexicana cuyo monto fue considerado como insignificante durante los debates en el Parlamento de Westminster, todas a su vez propiciaron el establecimiento del Imperio de Maximiliano.

\section{La deuda imperial y la doctrina republicana}

Entre 1864 y 1866 Maximiliano contrató cinco préstamos, dos de los cuales fueron renegociaciones de antiguas deudas mexicanas. El banco inglés Glyn Mills \& Co., otorgó dos créditos que fueron utilizados para pagar a las tropas francesas estacionadas en México desde enero de 1862, para cubrir gastos personales del Archiduque, desde vajillas hasta sueldos de sus emisarios y finalmente para pagar algunos adeudos a los London Bondholders e English Convention, pues de esta manera, y después de más de treinta años, con tal operación, ellos abrían para México el mercado de valores de Londres, así como también el de otras bolsas europeas, particularmente las de Ámsterdam y Frankfurt.

La entrada de México a las bolsas europeas era indispensable para promover cualquier otro préstamo dirigido a instalar un gobierno monárquico. El gobierno de Palmerston estuvo al tanto de estas operaciones crediticias y por ello mismo rompió la neutralidad, que de acuerdo al Derecho Internacional lo obligaba a interponerse para evitar cualquier tipo de financiamiento a una facción beligerante; ello, debido a que no solamente continuaba existiendo el gobierno de Juárez, sino que todavía 
Maximiliano no había sido investido como Emperador de México, ni reconocido como tal por Inglaterra u otras naciones.

El tercer préstamo se llamó el Tratado de Miramar también de 1864, el cuarto fue el contrato Fould-Oppenheim de 1865 y el quinto se 1lamó el Tratado Cesar-Dano de 1866. El monto total contratado y reconocido por Maximiliano superaba los 300 millones de pesos. Lo anterior quiere decir que hasta 1863, cuando el gobierno de Juárez tuvo que salir de la ciudad de México, la deuda total del país ascendía a 80 millones de pesos. Tres años después, el Imperio tenía sobre sí una deuda que había aumentado en 220 millones, lo que significaba un incremento de poco menos del 300 por ciento. De la deuda reconocida por el imperio, los créditos ingleses solo correspondían a 83 millones, una cuarta parte de la deuda imperial. Antes de 1863, la Deuda Inglesa representaba el 88 por ciento del total de la deuda de México. Las demás deudas que el país tenía con España, Francia y Estados Unidos tan solo eran un restante cercano al 12 por ciento.

Estas cifras son interesantes, pues demuestran que el peso financiero y político de la Deuda Inglesa disminuyó durante el Imperio de Maximiliano y que la mayor parte de los créditos fueron otorgados por banqueros e intereses franceses. Sin embargo, tal modificación no destruye a nuestro juicio la responsabilidad del banco inglés Glyn Mills \& Co. por haber proporcionado, y del gobierno británico por haber tolerado la flotación de tales préstamos, los cuales abrieron el mercado de créditos en Europa a la aventura francesa y le permitieron al Segundo Imperio Mexicano constituirse.

El triunfo republicano en 1867 cambió de raíz el problema de las deudas extranjeras y de las relaciones diplomáticas. Durante la Intervención Francesa, Juárez y sus ministros concibieron bajo los principios del derecho internacional las posibles consecuencias de una derrota del Imperio, de los actos emanados del régimen político y del reconocimiento diplomático otorgado por las naciones europeas.

La llamada Doctrina Juárez o Republicana establecía que fueron las potencias europeas quienes en 1861, unilateralmente y de modo presuroso, rompieron con el 
gobierno republicano. Respondiendo de la misma forma, el gobierno triunfante decidió expulsar a todos lo diplomáticos cuyos países reconocieron al Imperio de Maximiliano. La ruptura diplomática con España duró diez años de 1861 a 1871, con Francia 19 años de 1861 al 1880, con Inglaterra 23 años de 1861al 1884.

Las represalias no se detuvieron en los asuntos diplomáticos, en diciembre de 1867, el gobierno juarista declaró que dado que las potencias le habían hecho la guerra a México, por ese solo hecho, este gobierno daba por terminados todos los tratados bilaterales existentes. En este sentido quedaban sin efecto las convenciones diplomáticas referidas a las diversas deudas del país; asimismo, se subrayó que no se reconocerían los créditos contratados por el espurio gobierno de Maximiliano. Por lo tanto la deuda imperial era ilegítima, no así las deudas mexicanas anteriores a 1863 las cuáles tendrían que ser renegociadas. Más aún, se enfatizó que los adeudos legítimamente reconocidos serían de nueva cuenta asuntos mexicanos y de ninguna manera asuntos protegidos por las naciones europeas.

Entre 1867 y 1882 puede afirmarse que existió entre los gobiernos de Gran Bretaña y de México un total distanciamiento, a pesar de que en distintas ocasiones, diplomáticos mexicanos e ingleses conversaron sobre acabar con la ruptura existente pero ningún esfuerzo prosperaba. Por otro lado, los acreedores ingleses decidieron muy - a su pesar- negociar directamente con el gobierno mexicano.

A pesar de ello, el país empezó a comerciar grandes cantidades de artículos manufacturados procedentes de la Gran Bretaña y éste país continuó importando de México, plata y maderas preciosas. Más aun, inversionistas ingleses terminaron el primer ferrocarril entre Veracruz y la ciudad de México. Estos datos revelan que durante estos años por un lado existió un auténtico enfrentamiento entre los tenedores de bonos mexicanos y los nuevos inversionistas británicos. Los primeros ayudados por el Council of Foreign Bondholders mantenían cerradas las bolsas europeas para asuntos mexicanos. Por su parte, los nuevos inversionistas ingleses necesitaban créditos para fortificar el comercio bilateral y en el caso de las adminis- 
traciones mexicanas también requerían de dinero fresco para llevar a cabo las construcciones necesarias en la República.

Al llegar al poder el gral. Manuel González (1880-1884), desarrolló un amplio programa de obra pública y de fomento a la inversión extranjera. Durante el cuatrienio y debido al bloqueo ejercido por el London Stock Exchange, la red de ferrocarriles fue construida con capital americano. En 1882 se fundó el Banco Nacional Mexicano con capital franco-británico y dos años más tarde se fusionó con el Mercantil Mexicano - de capital español y mexicano - para crear el moderno Banco Nacional de México. Esta unión fue forzada por el régimen del presidente González, ya que a finales de su mandato el gobierno estaba quebrado y necesitaba que una entidad financiera le prestara importantes cantidades de dinero. Asimismo, se vio que el Banco Nacional podría ser el intermediario entre México y los acreedores ingleses. En octubre de 1884, el gobierno mexicano, la institución bancaria y los acreedores en Londres llegaron a un primer acuerdo reconociendo el monto de La Deuda Inglesa y estableciendo las formas de pago. Sin embargo, al llegar por segunda ocasión Díaz a la presidencia, desechó el acuerdo por antieconómico y contrario a los intereses mexicanos. La negociación definitiva se llevó a cabo en 1886 y fue terminada por el secretario de Hacienda, Manuel Dublán.

En 1886 México volvía a pagar, después de un cuarto de siglo, cuando en 1861 el gobierno de Benito Juárez declaró una moratoria por tan solo dos años.

La ruptura perpetrada por las potencias fue un acto resultante de años de negociaciones parcialmente cumplidas o incumplidas y sobre todo el convencimiento de que los mexicanos no eran de fiar, independientemente de su orientación política. El país fue invadido, varios miles de personas murieron, otros perdieron sus propiedades y muchos acreedores fallecieron sin haber recuperado su capital. El archiduque Maximiliano fue tan solo un objeto de los planes de la geopolítica imperial de la segunda mitad del siglo XIX, no solo de Napoleón 111, sino también de los gobiernos de Palmerston, de las intrigas vienesas en la corte de Francisco José, de las veleidades 
y corruptelas en Madrid entre otras. Después de un largo impasse diplomático y de una moratoria financiera, México recobró su crédito en pleno Porfiriato, pero los siguientes créditos fueron contratados con bancos alemanes y estadounidenses. Las casas bancarias inglesas y la City de Londres no estaban dispuestas a aventurar grandes sumas de dinero en lo que alguna vez fue llamada una República bohemia. Sin embargo, diversos inversionistas británicos continuaron desarrollando su actividad comercial, minera y en una empresa ferrocarrilera propiedad del vizconde de Cowdray, invierte en la realización de la vía Salina Cruz-Coatzacoalcos.

Hacia principios del siglo XIX la inversión inglesa fue la más importante en México, ésta situación se modificó paulatinamente hacia el final de la centuria convirtiendo a Estados Unidos en el primer socio comercial de México y la primera fuente de préstamos a largo plazo... hasta el día de hoy. 